\title{
THE PATIENTS' SATISFACTION FOLLOWING IMPLANT TREATMENT
}

\author{
Yoon-Young Heo ${ }^{1}$, Seong-Joo Heo ${ }^{2}$, DDS, MSD, PhD, \\ Myung-Woo Chang ${ }^{3}$, DDS, MSD, PhD, Ji-Man Park²*, DDS, MSD \\ ${ }^{\prime}$ Department of Chemistry, Wellesley College \\ ${ }^{2}$ Department of Prosthodontics, School of Dentistry, Seoul National University \\ ${ }^{3}$ Department of Prosthodontics, School of Dentistry, Harvard University
}

\section{INTRODUCTION}

The use of osseointegrated dental implants has become a successful procedure for the treatment of complete and partial edentulism. Numerous studies, both retrospective and prospective, have shown that edentulous patients were treated with osseointegrated implants for all applications, e.g. complete edentulism, ${ }^{1}$ partial edentulism, ${ }^{2-4}$ and more recently, single-tooth applications. ${ }^{5-7}$ Today, over 10000 publications on oral implants in humans are found in the literature. However, less than $2 \%$ of these studies deal with patient-centered outcomes of implant dentistry., Although patient-centered outcomes are usually not reported, these may represent major aspects of the implant success for the patient. ${ }^{10-13}$ Dental patients are better-informed consumers of dental services than they have been in the past. There are more dental practices available today, and patients can be more selective in their choice of dental practitioner. So the patient is a valuable information source for feedback to a dentist on how to improve treatment services. ${ }^{14,15}$ Use of a well-designed patient survey form can be an invaluable asset to the implant treatment practitioners. ${ }^{16}$

When assessing the outcomes of oral implant therapy, it is important to consider both the clinicians' and the patients' appraisals. ${ }^{17-19}$ For the clinician, implant survival, prosthesis longevity, and the frequency of complications are the most significant parameters. On the other hand, the social and psychological impact of the treatment, cost-effectiveness, benefit, and utility are more important from the patient' $s$ point of view. ${ }^{20,21}$ His/her degree of satisfaction depends on factors such as function, comfort, esthetics, any speech disruption. ${ }^{18,20}$

The objective of this study was to investigate patient satisfaction after implant therapy.

\section{MATERIALS AND METHODS}

\section{(1) Study population}

One hundred South Korean patients, who visited the dental examination center of Soon Chun Hyang university hospital from June to November 2008, participated in the study. The total number of patients who visited the center during this period was 2780 , thus the proportion of implant patient to total visited patient was 3.6 percent. The patients had a total of 263 implants placed to support or retain dental prostheses between 1994 and 2008 (used for 2.61 years on average). Four experimental groups of patients were distinguished as follows.

Group $\mathbf{A}_{1} / \mathbf{A}_{2} / \mathbf{A}_{3}$. Patients who were given implant treatment at a private dental office will be referred to as group $A_{1}$, who visited a dental clinic, where two or more dental departments were separated, as group $\mathrm{A}_{2}$, and who received a treatment at a dental university hospital as group A3. 22,23

Group $\mathbf{B}_{1} / \mathbf{B}_{2} / \mathbf{B}_{3}$. Patients who have been wearing the implant prosthesis less than three years will be referred to as group $\mathrm{B}_{1}$, from four to six years as group $\mathrm{B}_{2}$, and more than seven years as group $\mathrm{B}_{3}$.

Group $\mathbf{C}_{1} / \mathbf{C}_{2} / \mathbf{C}_{3}$. Patients who have single implant prosthesis will be referred to as group $\mathrm{C}_{1}$, who have a multiimplant splinted prosthesis as group $\mathrm{C}_{2}$, and who have a full 
arch implant prosthesis as $\mathrm{C}_{3}$.

Group $\mathbf{D}_{\mathbf{1}} / \mathbf{D}_{\mathbf{2}} / \mathbf{D}_{3}$. Patients who paid w 1,500,000 (KRW) or less for the implant treatment will be referred to as group $\mathrm{D}_{1}$, from $\mathrm{W} 1,500,000$ to $\mathrm{W}, 500,000$ as group $\mathrm{D}_{2}$, more than $w 2,500,000$ as group $D_{3}$.

\section{(2) Questionnaire design}

The patients mentioned were asked to give their perception on the implant therapy and allude to aspects of satisfaction using a questionnaire. After informed consent was obtained, each patient was asked to fill out a satisfaction questionnaire regarding aspects of cost, comfort, crown shape and color (esthetics), ability to eat, gum shape and color (gingival health), food impaction, phonetics, prosthesis loosening, and general satisfaction.

To compare the costs of the implant treatments, costs per tooth unit were estimated for all sorts of rehabilitation. Each patient' $s$ bill was divided by the number of units. All costs were quoted in Korean currency (KRW). Responses to statements were given on the Likert response scale, e.g. $5=$ strongly agree; 4 = agree; 3 = neither agree nor disagree; $2=$ disagree; 1 = strongly disagree for each of these parameters. ${ }^{24-26}$ When the score for a variable was high, patients were more satisfied. The questionnaire was completed unaided by the subject. Data collection was performed by a clinical research assistant unaware of the specific aims of this study.

\section{(3) Statistical analysis}

Data were entered into a spreadsheet (Excel 2007, Microsoft, Redmond, WA, USA), and all statistical analyses

Table I. Venue of implant treatment

\begin{tabular}{lc}
\hline Venue & $\%$ \\
\hline Private dental office $\left(\mathrm{A}_{1}\right)$ & 74 \\
Dental clinic $\left(\mathrm{A}_{2}\right)$ & 9 \\
Dental university hospital $\left(\mathrm{A}_{3}\right)$ & 17 \\
\hline
\end{tabular}

Table II. Prosthesis Characteristics

\begin{tabular}{lc}
\hline Prosthesis & $\%$ \\
\hline Single prosthesis $\left(\mathrm{B}_{1}\right)$ & 54 \\
Multi-unit prosthesis $\left(\mathrm{B}_{2}\right)$ & 43 \\
Full arch prosthesis $\left(\mathrm{B}_{3}\right)$ & 3 \\
\hline
\end{tabular}

were performed using SPSS statistical software for windows (release 14.0, SPSS Inc., Chicago, IL, USA). Multivariate analysis of variance (MANOVA) was used to find out factors which were correlated with patient satisfaction. The reliability of the response scales was measured by calculation of its internal consistency, expressed as Cronbach' s $\alpha$ (alpha). ${ }^{27}$ The scales were distinguished by means of factor analysis method performed on the pooled data and a maximum amount of variance for each factor was calculated. ${ }^{28,29}$ Possible differences in scale scores among the groups of patients were assessed by One-way analysis of variance (ANOVA) and post hoc Scheffe tests were used to determine differences between means $(\alpha=0.05)$.

\section{RESULTS}

\section{(1) Collected data}

A total of 100 patients answered to the questionnaire. The five-grade categorizing scale questionnaires were completed by all the patients. However, not all patients evaluated all the statements. The response rate ranged between $100 \%$ and $94.0 \%$ for the various aspects.

The patients were given implant treatment at a private dental office (74.0\%), a dental clinic (9\%), and a dental university hospital (17\%) (Table I). Implants were used to support single fixed partial dentures for the majority of the restorations (Table II).

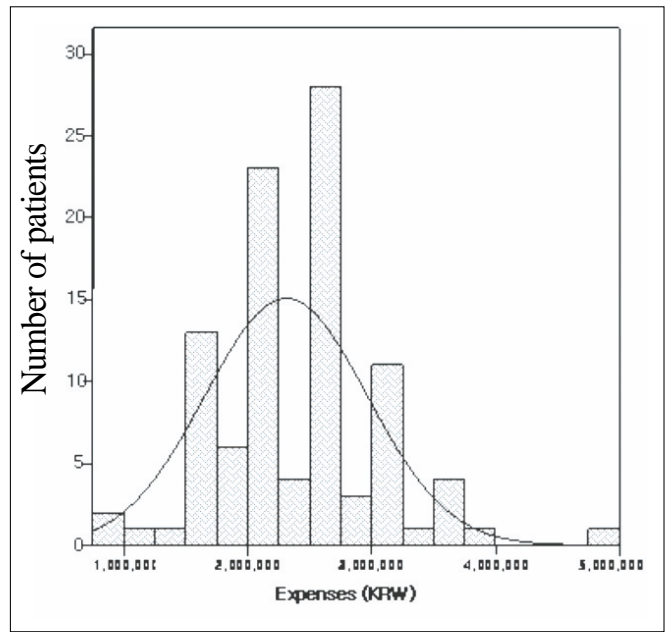

Fig. 1. Expenses for each implant. 
Table III. Categorized statements of the questionnaire and responses to the statements

\begin{tabular}{|c|c|c|c|c|c|}
\hline \multirow[b]{2}{*}{ Categorized statements } & \multicolumn{5}{|c|}{ Percentage of patients responded } \\
\hline & Strongly agree & Agree & $\begin{array}{l}\text { Neither agree } \\
\text { nor disagree }\end{array}$ & Disagree & $\begin{array}{l}\text { Strongly } \\
\text { disagree }\end{array}$ \\
\hline \multicolumn{6}{|c|}{ 1. The cost of the treatment was reasonable. } \\
\hline & 0 & 1 & 5 & 70 & 23 \\
\hline \multicolumn{6}{|c|}{ 2. I feel comfortable when I chew on my implant prosthesis. } \\
\hline & 20 & 52 & 21 & 6 & 1 \\
\hline \multicolumn{6}{|c|}{ 3. I am pleased with the esthetic results. } \\
\hline & 7 & 48 & 41 & 4 & 0 \\
\hline \multicolumn{6}{|c|}{ 4. I can chew on my crown or bridge very well. } \\
\hline & 17 & 41 & 35 & 7 & 0 \\
\hline \multicolumn{6}{|c|}{ 5. The tissue around the implant bleeds less than around the teeth. } \\
\hline & 31 & 42 & 23 & 3 & 1 \\
\hline \multicolumn{6}{|c|}{ 6. I haven't felt uncomfortable because of food packing during chewing. } \\
\hline & 14 & 29 & 38 & 14 & 5 \\
\hline \multicolumn{6}{|c|}{ 7. I can speak well with my crown or bridge. } \\
\hline & 28 & 49 & 19 & 4 & 0 \\
\hline \multicolumn{6}{|c|}{$\begin{array}{l}\text { 8. I haven t been to the clinic because the prosthesis had come loose and I feel securethat my implant prosthesis } \\
\text { will stay in place while eating and speaking. }\end{array}$} \\
\hline & 81 & 19 & 0 & 0 & 0 \\
\hline \multicolumn{6}{|c|}{ 9. I am satisfied with my implant prosthesis. } \\
\hline & 20 & 50 & 24 & 4 & 2 \\
\hline
\end{tabular}

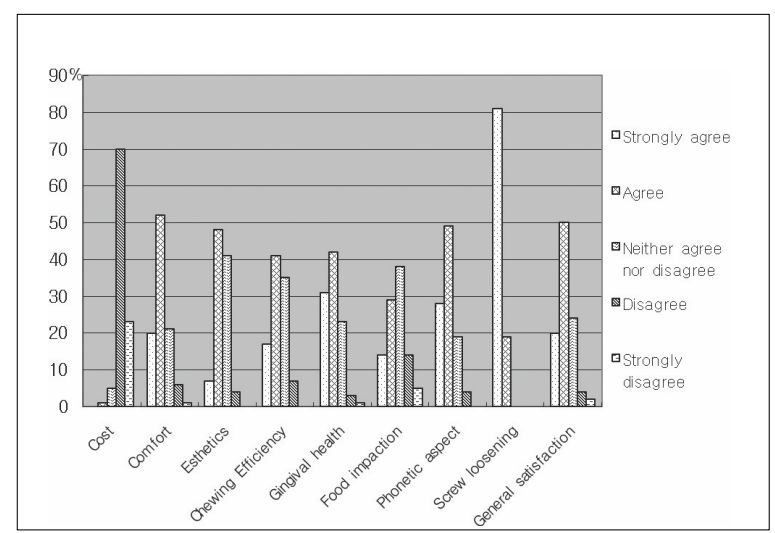

Fig. 2. Scale scores on the statements of questionnaire. When the score slants toward 'Strongly agree, patients were more satisfied.

Treatment expenses for each implant ranged from a minimum of $w 900,000$ to a maximum of $w 5,000,000$ (Fig. 1).

The categorized statements of the questionnaire and responses to the statements were shown in table III. Most of the responses were marked on 'strongly agree' or 'agree' scale, except the first statement about the cost for implant therapy. The scale scores on the statements were displayed in graph (Fig. 2, 3).

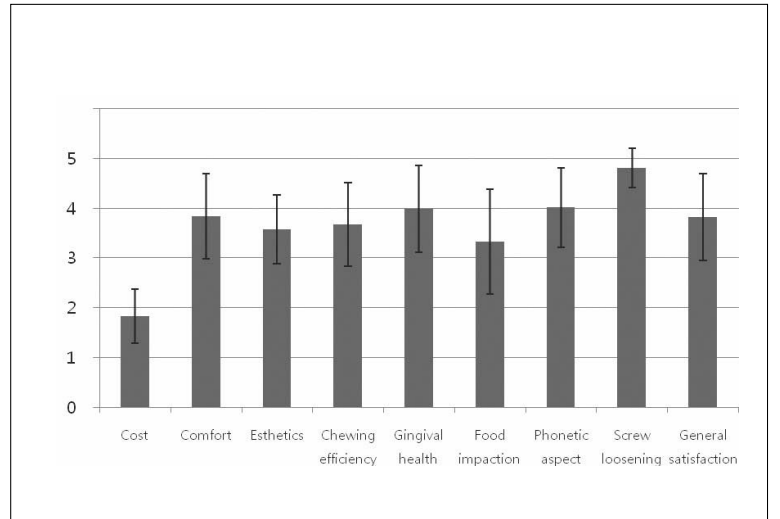

Fig. 3. Mean scale scores on the statements of questionnaire. When the mean score is near 5 , most of the patients, who completed the questionnaire, were highly satisfied.

\section{(2) Correlation among the statements}

Although the reliability of these scales proved to be fair to high, with Cronbach's alpha being 0.784 , values of 'Cronbach s alpha if item deleted' was higher than Cronbach s alpha in two statements (Cost of treatment:0.795, Screw loosening: 0.791). These two statements were removed and items were reconstructed. At the second reliability analysis, none of the statements made 
Table IV. Item-scale correlations and internal consistency

\begin{tabular}{|c|c|c|}
\hline \multirow{2}{*}{ Scale } & \multicolumn{2}{|c|}{ Cronbach's alpha if item deleted } \\
\hline & 1st analysis & 2nd analysis \\
\hline Cost of treatment & 0.795 & \\
\hline Comfort & 0.733 & 0.754 \\
\hline Esthetics & 0.761 & 0.783 \\
\hline Chewing efficiency & 0.747 & 0.769 \\
\hline Gingival health & 0.766 & 0.793 \\
\hline Food impaction & 0.773 & 0.805 \\
\hline Phonetic aspect & 0.772 & 0.801 \\
\hline Screw loosening & 0.791 & \\
\hline General satisfaction & 0.715 & 0.743 \\
\hline
\end{tabular}

Cronbach' s alpha (1st: 0.784, 2nd: 0.805)

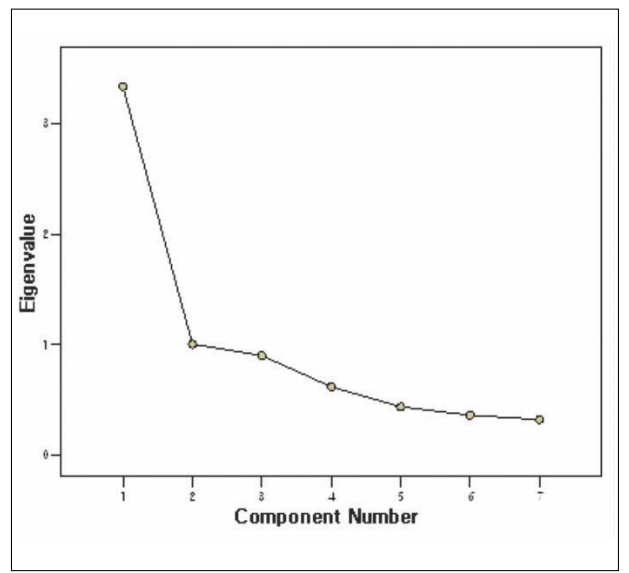

Fig. 4. Scree Plot.
Table V. Total variance explained

\begin{tabular}{cccc}
\hline \multirow{2}{*}{ Component } & \multicolumn{3}{c}{ Eigenvalues } \\
\cline { 2 - 4 } & Total & \% of Variance & Cumulative \% \\
\hline 1 & 3.39 & 47.69 & 47.69 \\
2 & 1.01 & 14.39 & 62.08 \\
3 & 0.9 & 12.92 & 74.99 \\
4 & 0.62 & 8.88 & 83.87 \\
5 & 0.44 & 6.29 & 90.16 \\
6 & 0.36 & 5.2 & 95.36 \\
7 & 0.33 & 4.64 & 100 \\
\hline
\end{tabular}

Table VI. List of extracted factors

\begin{tabular}{lcc}
\hline Statements & Factor 1 & Factor 2 \\
\hline General satisfaction & 0.835 & \\
Comfort & 0.808 & \\
Chewing efficiency & 0.744 & \\
Esthetics & 0.676 & \\
Phonetic aspect & 0.556 & \\
Food impaction & & 0.678 \\
Gingival health & & 0.21 \\
\hline
\end{tabular}

Extraction Method: Principal Component Analysis.

2 components extracted.

Table VII. Mean scale scores and standard deviations for groups B1, B2, and B3 on the esthetics scale and differences between groups (ANOVA)

\begin{tabular}{cccccccccccc}
\hline \multirow{2}{*}{ Scale } & \multicolumn{2}{c}{$\mathrm{B}_{1}$} & \multicolumn{2}{c}{$\mathrm{B}_{2}$} & \multicolumn{2}{c}{$\mathrm{B}_{3}$} & & \multicolumn{3}{c}{ Scheffé } \\
& Mean & STDEV & Mean & STDEV & Mean & STDEV & F & Df & P \\
\hline Esthetics & 3.54 & 0.76 & 3.5 & 0.58 & 4.08 & 0.29 & 3.59 & 2 & 0.032 & $\mathrm{~B}_{1}<\mathrm{B}_{3}$ \\
\hline
\end{tabular}

Cronbach's alpha value (0.805) larger when the item was deleted (Table IV).

As the first two eigenvalues of the correlation matrix went beyond 1.0, the number of factors could be two by the Kaiser' s rule (Table V). ${ }^{26}$ A repeated analysis with the 7 variables revealed two factors, with most of the variables having a factor loading that exceeded 0.40 and loading on one factor only. The totally extracted variance was $62.1 \%$ (factor 1, 47.7\%; factor 2, 14.4\%). The first principle factor analysis resulted in five components, e.g. general satisfaction, comfort, chewing efficiency, esthetics, and phonetic aspect (Table VI). Two components, e.g. food impaction, and gingival health could be grouped as factor 2 . Because the inclination of line between component 1 and 2 was steeper than any other inclination in the Scree plot (Fig. 4) and the percent of variance for component 1 was largest among seven components (Table V), factor 1 could explain the greater part of scale scores. The percent of variance for component 2 was relatively small, so factor 2 could not be classified clearly and the meaning they carry was less significant.

\section{(3) Differences between groups of patients}

There was no statistically significant difference among group $A_{1}, A_{2}$, and $A_{3}$ on any of the scales, indicating that there wasn' $t$ great difference of implant treatment at private dental office, dental clinic, and dental university hospital $(P>.05)$. 
Among group $\mathrm{B}_{1}, \mathrm{~B}_{2}$, and $\mathrm{B}_{3}$, there was significant difference on the esthetics scale $(P=.032)$. Patients who have been wearing the implant prosthesis more than seven years felt the largest satisfaction $\left(\mathrm{B}_{1}<\mathrm{B}_{3}\right)$ (Table VII).

There wasn' $t$ any difference of satisfaction irrespective of how many implants the patient has or how much the cost of implant treatment was (C or D).

\section{DISCUSSION}

The current study was limited to patients visiting dental examination center of Soon Chun Hyang university hospital. This hospital is located at the center of Seoul close to Han River, and the middle class of the Seoul citizens are the key customers of this center.

A survey questionnaire was distributed to patients for completion while they were waiting for their appointment rather than mailing it to them in this study. This strategy would eliminate mailing costs and the personal input survey technique tends to increase the response rate. However, care must be taken to provide anonymity in order to obtain candid responses. ${ }^{16}$

Although patients responded to most of the statements with high satisfaction, mean scale score of statement about cost was significantly low, and that of food impaction was slightly lower than the other statements. Treatment costs and comparative economic analyses are increasingly the subjects of discussion in the dental literature. ${ }^{17-21}$ Pjetursson et al. ${ }^{8}$ reported in his study that the costs associated with implant therapy in Switzerland were considered to be justified, while Tepper et al..$^{30}$ described the implantsupported rehabilitation to be very expensive in Austria. The goals of our study were to investigate patients' assessments of and satisfaction with the treatment outcomes and to consider the cost-effectiveness of the applied treatment options. The overall negative results from the questionnaire indicate that cost-utility and cost-benefit did not justify the extra expense for Korean people. Although the health insurance system of South Korea is well established and most of dental services are provided with financial support, implant treatment is not covered by insurance and costs a lot. Because Korean food is mostly tough, Koreans rate the replacement of edentulous span with implant teeth very high and expensive price of implant treatment might have been one of complaints. However, a longer observation period is necessary to include measures such as the number of years the prosthesis lasts, the won (KRW) values per year, and the patient's estimate of the importance of these years. ${ }^{19}$ Food impaction was one of the major complaints of posterior implant prosthesis due to narrow diameter of implant fixture and rapid widening of emergence profile, and this was revealed on this study.

Cronbach' $\mathrm{s}$ alpha is a statistic which has an important use as a measure of the reliability of a psychometric instrument. It was first named as alpha by Cronbach. Cronbach's alpha will generally increase when the correlations between the items increase. For this reason the coefficient is also called the internal consistency reliability of the test. ${ }^{27}$ Factor analysis is a statistical method used to explain variability among observed variables in terms of fewer unobserved variables called factors. The observed variables are modeled as linear combinations of the factors, plus "error" terms. Eigenvalue is a weighted sum of squared correlations, with each correlation weighted by the variance of the corresponding variable. Henry Kaiser suggested a rule for selecting a number of factors less than the number needed for perfect reconstruction: set the number of factors equal to the number of eigenvalues greater than $1 .^{26}$ The information gained about the interdependencies can be used later to reduce the set of variables in a dataset. Factor analysis originated in psychometrics, and is used in behavioral sciences, social sciences, marketing, and other applied sciences that deal with large quantities of data. ${ }^{28,29}$ After the verification of internal consistency and factor analysis, five components, e.g. general satisfaction, comfort, chewing efficiency, esthetics, and phonetic aspect were grouped together. It could be said that these components were explained with common meaning; hence comfort, chewing efficiency, esthetics, and phonetic aspect were correlated and the first factor was named as 'general satisfaction'. The other components, e.g. food impaction, and gingival health were grouped as factor 2, and this factor was named as 'complication' .

Differences in patient satisfaction on the scale with esthetics were present between patients who have been wearing the implant prosthesis less than three years and those more than seven years $\left(B_{1}<B_{3}\right)$. It seems that the patients who got the implant prosthesis more recently have 
higher expectations for the esthetics of resultant prosthesis, and a trend about esthetic implant has been known to the general public. The scores on the scales among groups A, $\mathrm{C}$, and D did not differ to a statistically significant level. However, these findings must be interpreted with caution because patients could not, for ethical reasons, be randomly assigned.

\section{CONCLUSION}

The patients in the present study were generally satisfied with the outcome of implant treatment. But the patients' major complaint was high cost for the implant treatment. And while the statistically significant difference was not shown, the satisfaction scale about food impaction and esthetics was also a little low. So the continuing efforts to make improvements about these problems are needed for the implant practitioners. Patient satisfaction surveys can be an invaluable tool if they are well designed, the information is interpreted properly, and the response to the findings appropriate. Further study is required for extrapolation of the results of this study and confirmation of their generality.

\section{REFERENCES}

1. Adell R, Lekholm U, Rockler B, Brånemark PI. A 15-year study of osseointegrated implants in the treatment of the edentulous jaw. Int J Oral Surg 1981;10:387-416.

2. Lekholm U, van Steenberghe D, Herrmann I, Bolender C, Folmer T, Gunne J. Osseointegrated implants in the treatment of partially edentulous jaws: A prospective 5-year mulitcenter study. Int J Oral Maxillofac Implants 1994;9:627-35.

3. Buser D, Mericske-Stern R, Bernard JP, Behneke A, Behneke N, Hirt HP, Belser VC, Lang NP. Long-term evaluation of non-submerged ITI implants. Part 1: 8-year life table analysis of a prospective multi-center study with 2359 implants. Clin Oral Implants Res 1997;8:161-72.

4. Lekholm U, Gunne J, Henry P, Higuchi K, Lindén U, Bergström C, van Steenberghe D. Survival of the Branemark implant in partially edentulous jaws: a 10 -year prospective multicenter study. Int J Oral Maxillofac Implants 1999;14:639-45.

5. Jermt T, Pettersson P. A 3-year follow-up study on single implant treatment. J Dent 1993;21:203-8.

6. Henry PJ, Laney WR, Jemt T, Harris D, Krogh PH, Polizzi G, Zarb GA, Herrmann I. Osseointegrated implants for sin- gle-tooth replacement: a prospective 5-year multicenter study. Int J Oral Maxillofac Implants 1996;11:450-5.

7. Chang M, Wennström JL, Odman P, Andersson B. Implant supported single-tooth replacements compared to contralateral natural teeth. Crown and soft tissue dimensions. Clin Oral Implants Res 1999;10:185-94.

8. Pjetursson BE, Karoussis I, Bürgin W, Brägger U, Lang NP. Patients' satisfaction following implant therapy. A 10year prospective cohort study. Clin Oral Implants Res 2005;16:185-93.

9. de Grandmont P, Feine JS, Taché R, Boudrias P, Donohue WB, Tanguay R, Lund JP. Within-subject comparisons of implant-supported mandibular prostheses: psychometric evaluation. J Dent Res 1994;73:1096-104.

10. Allen PF, McMillan AS, Walshaw D. Patient expectations of oral implant-retained prostheses in a UK dental hospital. Br Dent J 1999;186:80-4.

11. Clancy JM, Buchs AU, Ardjmand H. A retrospective analysis of one implant system in an oral surgery practice. Phase I: Patient satisfaction. J Prosthet Dent 1991;65:26571.

12. Schropp L, Isidor F, Kostopoulos L, Wenzel A. Patient experience of, and satisfaction with, delayed-immediate vs. delayed single-tooth implant placement. Clin Oral Implants Res 2004;15:498-503.

13. Assunção WG, Zardo GG, Delben JA, Barão VA. Comparing the efficacy of mandibular implant-retained overdentures and conventional dentures among elderly edentulous patients: satisfaction and quality of life. Gerodontology 2007;24:235-8.

14. Siadat H, Alikhasi M, Mirfazaelian A, Geramipanah F, Zaery F. Patient satisfaction with implant-retained mandibular overdentures: a retrospective study. Clin Implant Dent Relat Res 2008;10:93-8.

15. Liddelow GJ, Henry PJ. A prospective study of immediately loaded single implant-retained mandibular overdentures: preliminary one-year results. J Prosthet Dent 2007;97:12637.

16. Haisch MA. Outcomes assessment survey to determine patient satisfaction. J Contemp Dent Pract 2000;1:89-99.

17. Anderson JD. The need for criteria on reporting treatment outcomes. J Prosthet Dent 1998;79:49-55.

18. Locker D. Patient-based assessment of the outcomes of implant therapy: a review of the literature. Int J Prosthodont 1998;11:453-61.

19. Zitzmann NU, Marinello CP. Treatment outcomes of fixed or removable implant-supported prostheses in the edentulous maxilla. Part I: patients' assessments. J Prosthet Dent 2000;83:424-33.

20. Guckes AD, Scurria MS, Shugars DA. A conceptual framework for understanding outcomes of oral implant therapy. J Prosthet Dent 1996;75:633-9. 
21. Lewis DW. Optimized therapy for the edentulous predicament: cost-effectiveness considerations. J Prosthet Dent 1998;79:93-9.

22. Sonis ST, Fazio R, Setkowicz A, Gottlieb D, Vorhaus C. Comparison of the nature and frequency of medical problems among patients in general, specialty and hospital dental practices. J Oral Med 1983;38:58-61.

23. Nery EB, Meister F Jr, et al. Ellinger RF, Eslami A, McNamara TJ. Prevalence of medical problems in periodontal patients obtained from three different populations. J Periodontol 1987;58:564-8.

24. Likert R. A technique for the measurement of attitudes. Archives of Psychology 1932;140:1-55.

25. Likert R. Public opinion polls. Sci Am 1948;179:7-11.

26. Wolfle D, Likert R, et al. Standards for appraising psychological research. Am Psychol 1949;4:320-8.
27. Cronbach LJ. Coefficient alpha and the internal structure of tests. Psychometrika 1951;16:297-334.

28. Guilford JP, Frutcher B. Fundamental statistics in psychology and education. 5th ed. New York;McGraw Hill; 1973. pp. 121-34.

29. Nunnally JC. Psychometric theory. 2nd ed. New York;McGraw Hill; 1978. pp. 278-92.

30. Tepper G, Haas R, Mailath G, Teller C, Bernhart T, Monov G, Watzek G. Representative marketing-oriented study on implants in the Austrian population. II. Implant acceptance, patient-perceived cost and patient satisfaction. Clin Oral Implants Res 2003;14:634-42. 


\title{
THE PATIENTS’ SATISFACTION FOLLOWING IMPLANT TREATMENT
}

\author{
Yoon-Young Heo', Seong-Joo Heo ${ }^{2}$, DDS, MSD, PhD, \\ Myung-Woo Chang ${ }^{3}$, DDS, MSD, PhD, Ji-Man Park ${ }^{2 *}$, DDS, MSD \\ ${ }^{1}$ Department of Chemistry, Wellesley College \\ ${ }^{2}$ Department of Prosthodontics, School of Dentistry, Seoul National University \\ ${ }^{3}$ Department of Prosthodontics, School of Dentistry, Harvard University
}

STATEMENT OF PROBLEM: While patient-centered outcomes are usually not reported, these may represent major aspects of the implant success for the patient. Use of a well-designed patient survey form can be an invaluable asset to the implant practitioners. PURPOSE: The objective of this study was to investigate patient satisfaction after implant therapy by means of a questionnaire. MATERIAL AND METHODS: South Korean patients $(n=100)$, who visited the dental examination center of Soon Chun Hyang university hospital, were asked to fill out the satisfaction questionnaire regarding aspects of cost, comfort, esthetics, chewing, gingival health, food impaction, phonetic aspect, screw loosening, and general satisfaction. Responses to statements were given on the Likert response scale. Four experimental groups of patients were distinguished with various location $\left(A_{1}, A_{2}, A_{3}\right)$, year $\left(B_{1}, B_{2}, B_{3}\right)$, number of implant replacements $\left(C_{1}, C_{2}, C_{3}\right)$, and treatment cost $\left(\mathrm{D}_{1}, \mathrm{D}_{2}, \mathrm{D}_{3}\right)$. The reliability of the response scales was measured by calculation of its internal consistency, expressed as Cronbach's $\alpha$. The scales were distinguished by means of factor analysis method. Possible differences in scale scores among the groups were assessed by One-way ANOVA $(\alpha=0.05)$. RESULTS: Patients responded to most of the statements with high satisfaction. But the mean scale score of statement about cost was low. After the verification of internal consistency and factor analysis, five components, e.g. general satisfaction, comfort, chewing efficiency, esthetics, and phonetic aspect were grouped together. These components could be explained with common meaning and the first factor was named as 'general satisfaction'. Differences in patient satisfaction on the scale with esthetics were present between patients who have been wearing the implant prosthesis less than three years and those more than seven years $\left(\mathrm{B}_{1}<\mathrm{B}_{3}\right)$. CONCLUSION: The patients were generally satisfied with the outcome of implant treatment. But the patients' major complaint was high cost and while the statistically significant difference was not shown, the satisfaction scale about food impaction and esthetics was low. So the continuing efforts to make improvements about these problems are needed for the implant practitioners.

KEY WORDS: Dental implant, Patient satisfaction, Questionnaire, Likert scale, Internal consistency, Factor analysis 